\title{
ПСИХОЛОГИЧЕСКИЕ МОДЕЛИ ЛИЦ, ЗАНИМАЮЩИХ РУКОВОДЯЩИЕ ДОЛЖНОСТИ, И ОЦЕНКА ЭФФЕКТИВНОСТИ ПРЕОДОЛЕНИЯ ИМИ СТРЕССОВЫХ СИТУАЦИЙ
}

\section{PSYCHOLOGICAL MODELS OF PERSONS HOLDING MANAGERIAL POSITIONS AND ASSESSMENT OF THE EFFECTIVENESS OF OVERCOMING STRESSFUL SITUATIONS}

\section{Sinayskiy}

Summary: The article analyzes the problem of psychological characteristics of managers in terms of the effectiveness of overcoming stressful situations. Psychological models of managers ' personality are considered from the point of view of collection and functional approaches. These psychological models allow us to describe professionally important qualities and abilities of managers that allow them to successfully perform managerial functions not only in standard, but also in stressful situations. Psychological qualities and abilities, features of managers' behavior coping with stress that allow them to successfully cope with stressful situations that accompany managerial work are highlighted.

Keywords: manager, managerial activity, stress, professionally important qualities, coping behavior.
Синайский Дамиан Димитрианович

Генеральный директор, ООО «Центр стратегического коучинга и психотерапии Дамиана Синайского»

damiansynaysky@gmail.com

Аннотация: В статье проведен анализ проблемы психологических особенностей руководителей с точки зрения эффективности преодоления ими стрессовых ситуаций. Рассмотрены психологические модели личности руководителей с позиции коллекционного и функционального подходов. Данные психологические модели позволяют описать профессионально-важные качества и способности руководителей, позволяющие успешно выполнять управленческие функции не только в стандартных, но и в стрессовых ситуациях. Выделены психологические качества и способности, особенности совладающего со стрессом поведения руководителей, позволяющие успешно справляться со стрессовыми ситуациями, которые сопровождают управленческий труд.

Ключевые слова: руководитель, управленческая деятельность, стресс, профессионально-важные качества, совладающее поведение.

ность нагрузок. У руководителей среднего звена выражены негативные субъективные оценки затруднений в актуальной трудовой ситуации, которая характеризуется высоким разнообразием и когнитивной сложностью задач и низкой автономией исполнения [4]. Указанные факторы управленческого труда характеризуются как стресс-факторы, обуславливающие высокую психическую напряженность профессиональной деятельности руководителя. В связи с этим необходимым становится исследование личности руководителя и его психологических особенностей в русле оценки способности к эффективному преодолению стрессовых ситуаций, возникающих в управленческой деятельности.

Раскроем понимание понятия профессиональный стресс руководителей. Анализ профессионального стресса ориентирован, прежде всего, на выявление специфики проявлений стресса в связи с профессиональной принадлежностью к определенной сфере профессиональной деятельности, в частности к условиям управленческой деятельности. Согласно взглядам современных исследователей, профессиональный стресс является результатом дисбаланса между наличными 
внутренними ресурсами руководителя и требованиями внешней среды, воплощенными в особенностях конкретной трудовой ситуации [1]. А.А. Качиной отмечается, что при взаимодействии руководителя и стрессогенной ситуации симптомы стресса имеют отличия в зависимости от стажа управленческой деятельности. У молодых руководителей отмечаются выраженные проявления депрессии и признаки синдрома выгорания, характерные для начальных периодов вхождения в профессию. Для руководителей старшего возраста характерно накопление эффектов хронического утомления и признаки нарастающего истощения, не связанные с формированием профессионально обусловленных личностных деформаций. Для руководителей высшего звена в качестве основных источников стресса выступают внешние факторы, к которым относятся напряженные условия труда, неоптимальная организация работы, высокая интенсивность нагрузок [4].

Выявлены общие признаки и отличия, как в стрессовых ситуациях, так и в симптомах стресса у лиц, занимающих руководящие должности в зависимости от должностного статуса. У руководителей высшего и среднего звена стрессовые ситуации не имеют различий в сфере осуществления внутренней функции управления и контроля за подчиненными, но отличаются степенью ответственности спецификой круга делового взаимодействия и величиной финансовых рисков [5, с. 149]. В синдромах стресса у руководителей высшего звена имеют место выраженные признаки психофизиологического истощения, тревоги и депрессии, усугубляемые доминирующим типом А поведения и использованием неадекватных поведенческих форм купирования стресса. У руководителей среднего звена профессиональный стресс выражается в фиксации устойчивых переживаний тревоги и агрессии, дополняющихся наличием невротических реакций [4].

Анализируя профессиональный стресс руководителей, обратимся к мнению Т.Л. Крюковой, которая акцентирует внимание на психологическом содержании стресса. В отличие от физиологического стресса, при психологическом стрессе необходимо учитывать такие факторы, как «значимость ситуации для субъекта, особенностей интеллектуальных процессов, личностных характеристик..., которые обусловливают и специфику ответных реакций» $[6$, с. 20]. Степень проявления стрессовых реакций у конкретного руководителя зависит от специфики эмоционально-личностной сферы, индивидуального опыта и контекста групповых и организационных взаимодействий, в рамках которых осуществляется управленческая деятельность.

Сложность ответных реакций на стрессовую ситуацию вызывают необходимость исследования психологических предпосылок и закономерностей проявления тех или иных внешних реакций в стрессовой ситуации у лиц, занимающих руководящую должность. Анализируя природу психологического и профессионального стресса, В.А. Бодров указывает, что «они отражают два ракурса содержательных характеристик стресса: с одной стороны, процессуальную и регулятивную, с другой стороны предметную и коррелятивную» [1, с. 48]. Поэтому исследование психологических особенностей преодоления стрессовой ситуации у руководителей предполагает изучение, с одной стороны, комплекса психологических характеристик личности руководителей, способствующих снижению стресса, с другой - особенностей и способов совладания со стрессом.

В научной психологической литературе распространенным подходом к описанию психологической модели личности руководителей является коллекционный подход, в основе которого лежит комплекс профессионально-важных качеств (далее ПВК) личности руководителя. Под профессионально важными качествами В.Д. Шадриков понимает «индивидуальные качества субъекта деятельности, влияюлщие на эффективность деятельности и успешность ее освоения» [9, с. 65]. Более развернуто определяют содержание ПВК А.Е. Горбушин, Ю.А. Сауров, согласно которым ПВК руководителя включают «особенности мотивационной, эмоционально-волевой и интеллектуальной сферы личности, особенности профессионального самосознания, социально-психологические способности и умения, связанные с процессами межличностного взаимодействия, психофизиологические особенности, определяющие в совокупности активность, работоспособность и выносливость, а также опыт, запас профессиональных знаний, умений и навыков» [2, c. 171-172].

С позиции функционального подхода к психологической модели личности руководителей, В.Д. Шадриков выделяет умственные способности, позволяющие решать разноплановые задачи; потребность к организаторской деятельности, а также высокий уровень компетентности, включающий знание производственных технологий и умение сформировать производственный коллектив. Наличие данных психологических качеств и способностей руководителя позволяют осуществлять основные управленческие функции, такие как планирование и прогноз, организация и управление, мотивация и контроль [9, с. 186].

Интерес представляет исследование личностных детерминант лиц, занимающих руководящие должности, которые обеспечивают эффективность преодоления ими стрессовых ситуаций и могут рассматриваться как ПВК руководителей. В.А. Бодров заявляет, что эффективное преодоление стресса вязано с такими личностными образованиями, как локус контроля и самооценка. Руководители с внутренним локусом контроля и с высокой самооценкой позитивно оценивают собственные ресур- 
сы приспособления к стрессогенной ситуации в управленческой деятельности [1]. Согласно результатам исследования А.А. Качиной, на особенности преодоления стресса влияют мотивационно-ценностные образования личности руководителей. Так, в группе молодых управленцев развитие стресса связано с влиянием социально ориентированных мотивационных установок, которые находят отражение в потребности в самоутверждении, в развитии карьеры и в повышении профессионального статуса. У руководителей старшего возраста в развитии стресса ключевую роль играют личностно ориентированные установки, которые связаны с уровнем притязаний, потребностью в самоактуализации и самоуважении [4].

В психологической модели руководителя Л.В. Фаткина, наряду с адаптационной мобильностью, лидерством, способностью к интеграции социлальных ролей, способностью к открытому общению, выделена интеллектуальная, волевая и эмоциональная стрессоустойчивость руководителя [9, с. 186]. В.И. Моросановой подчеркивается, что успешность управленческой деятельности обеспечивается сформированностью целостной системы саморегуляции личности руководителя, а любой структурно-функциональный дефект процесса регуляции существенно лимитирует успешность и эффективность деятельности руководителя [7].

В этой связи интерес вызывает проблема развития стрессоустойчивости руководителей как условия, снижающего риск возникновения профессионального стресса. Стрессоустойчивость означает «стабильность функций организма и психики при воздействии стрессфакторов, их резистентность (сопротивляемость) и толерантность (выносливость) к экстремальным воздействиям..., способность компенсировать чрезмерные функциональные сдвиги (нарушения) при воздействии стрессоров» [1, с. 262]. Рассматривая стрессоустойчивость как «адаптацию к эмоционально значимой ситуации, можно выделить две стадии: первая стадия - стадия эмоциональной реактивности, которая характеризуется вегетативными сдвигами, возникающими в организме под влиянием эмоциогенного воздействия; вторая стадия - эмоциональная адаптация к возникшим в организме вегетативным сдвигам. Смысл эмоциональной устойчивости состоит в подавлении возникших вегетативных сдвигов и саморегуляции, направленной на сохранение целесообразного поведения» [3, с. 11]. Итак, стрессоустойчивость включает эмоциональную устойчивость и способность регуляции функционального состояния в напряженной, стрессогенной деятельности, к которой относится и управленческая деятельность руководителей.

Развитие стрессоустойчивости личности руководителей предполагает необходимость рассмотрения проблемы совладающего (coping) поведения, которое представляет собой механизмы эмоциональной и рациональной регуляции своего поведения с целью оптимального взаимодействия со стрессом. Специфические стратегии стресс-преодолевающего поведения руководителей реализуются в конкретных ситуациях профессиональной деятельности. Изменение характера стрессовых ситуаций приводит к изменению способов стресс-преодолевающего поведения. На стресспреодолевающее поведение руководителей влияет множество факторов, к которым относятся, согласно Т.Л. Крюковой «оценка степени угрозы; оценка ресурсов, необходимых для совладания с ситуацией; оценка собственных действий, их успешности в преодолении стресса» [6, с. 23]. Выбор способов стресс-преодолевающего поведения детерминирован как особенностями личности, так и особенностями ситуации. Поэтому особое внимание при исследовании профессионального стресса руководителей необходимо уделять чертам и свойствам личности, обеспечивающим выбор эффективных способов стресс-преодолевающего поведения. Нарушение нормального функционирования, ухудшение здоровья и другие негативные последствия стресса связываются с недостаточностью ресурсов и эффективностью стратегий совладающего со стрессом поведения [6].

Многообразие стрессогенных ситуаций и факторов управленческой деятельности, особенности личностных детерминант, обуславливающих реагирование на стресс, обусловливают различные способы преодолевающего поведения руководителей в стрессовых ситуациях профессиональной деятельности. Исследуя особенности стрессового реагирования у руководителей высшего и среднего звена, О.А. Ковалева рассматривает различные стрессовые ситуации как психологические барьеры, которые вызывают стрессовые состояния у руководителей. Стрессовые ситуации запускают способы совладающего поведения у руководителей, которые не имеют различий от их должностного статуса. Преобладающим стилем совладания со стрессом, как у руководителей среднего звена, так и у руководителей высшего звена является проблемно-ориентированный копинг. Как отмечает автор «чаще всего при возникновении стрессовых ситуаций руководители обращаются к анализу проблемы, ее решению, направляют свои усилия на изменение трудной ситуации» [5, с. 149].

Таким образом, в психологической модели лиц, занимающих руководящую должность, стрессоустойчивость как способность сохранять высокий уровень эффективности деятельности в напряженныхусловияхпрофессиональной деятельности, является профессионально-важным качеством. Высокий уровень стрессоустойчивости снижает риск использования неэффективных стратегий совладания и позволяет успешно противодействовать возникновению стресса у руководителей. 


\section{ЛИТЕРАТУРА}

1. Бодров В.А. Информационный стресс. - М.: Пер Сэ., 2000.- 352 с.

2. Горбушин А.Е. Вопросы методологии управленческой деятельности / А.Е. Горбушин, Ю.А. Сауров. - Киров, 2003. - 272 с.

3. Долгова В.И. Формирование эмоциональной устойчивости / В.И. Долгова, М.Ю. Буслаева. - Челябинск, изд-во РЕКПОЛ, 2010. - 205 С.

4. Качина А.А. Психологическая структура профессионального стресса у менеджеров разного должностного статуса: дис. .... канд. психологических наук. Москва, 2006. - 163 c.

5. Ковалева 0.А. Совладание руководителей со стрессом на рабочем месте // Вестник КГУ им. Н.А. Некрасова. - 2013. - № 4 (19). - С. 148-151.

6. Крюкова Т.Л. Психология совладающего поведения в разные периоды жизни: дис. ... доктора психологических наук. - Кострома, 2005. - 473 с.

7. Моросанова В.И. Саморегуляция и индивидуальность человека. - М.: Наука, 2012. - 519 с.

8. Урбанович, А.А. Психология управления: учеб. пособие. - Мн: Харвест, 2007. - 640 с.

9. Шадриков В.Д. Психология деятельности и способности человека: Учебное пособие. - М.: Издательская корпорация Логос, 1996. - 320 c.

() Синайский Дамиан Димитрианович (damiansynaysky@gmail.com) 